\title{
UNA VISIÓN POÉTICA DEL CARIBE EN LA OBRA DE RAÚL GÓMEZ JATTIN
}

Hernando Motato 


\title{
UNA VISIÓN POÉTICA DEL CARIBE EN LA OBRA DE RAÚL GÓMEZ JATTIN*
}

\begin{abstract}
Resumen: este artículo está centrado en la percepción del Caribe a través de la poesía de Gómez Jattin. En él se focaliza cómo el poeta recrea aspectos de la cultura representados en la música y la incidencia de esta manifestación artística en las formas de pensamiento y actitud ante la realidad cotidiana, pues el hombre del Caribe hace de la música una manera de explicarse su mundo, tal como se reseña en el recorrido de las diversas manifestaciones musicales a lo largo y ancho de la cultura caribeña. También se destaca el caso de la zoofilia como una afirmación de las formas de vida o bien en la ensoñación de lo telúrico a partir de los atardeceres, los frutos de la tierra y la idealización de los pueblos, como san Pelayo y Cereté. Desde esta perspectiva la poesía de Gómez Jattin exalta el sentido y la esencia del ser caribeño a lo largo de la Historia y su trascendencia cultural.
\end{abstract}

Palabras clave: poesía, cultura, Caribe, música e identidad.

\section{A POETIC VISION OF THE CARIBBEAN IN GÓMEZ JATTIN'S POETRY}

\begin{abstract}
Caribbean through Gómez Jattin's poetry. It shows how the poet recreates cultural aspects represented in music and its incidence in ways of thinking and attitudes towards reality, for the Caribbean man uses music as a way of explaining his world, as shown by the observation of the diverse musical manifestations throughout the Caribbean culture. It also highlights zoophilia as an affirmation of the ways of living or the dream of the telluric ambit from sunsets, fruits of the earth, and the idealization of such towns as San Pelayo and Cereté. From this perspective, Gómez Jattin's poetry exalts the meaning end essence of being Caribbean through history and its cultural transcendence.
\end{abstract}

Keywords: poetry, culture, Caribbean, music and identity.

Fecha de recepción: julio 16 de 2014

Fecha de aceptación: julio 27 de 2015

Forma de citar: Motato, H. (2015). "Una visión poética del caribe en la obra de Raúl Gómez Jattin". Revista Filosofía UIS. 14 (2). pp. 209-224.

Hernando Motato: colombiano. Profesor de la Escuela de Idiomas. Universidad Industrial de Santander-Colombia.

Correo electrónico:jhmotato@yahoo.com

\footnotetext{
* Documento de reflexión no derivado de investigación.
} 


\section{UNA UISIÓN POÉTICA DEL CARIBE EN LA OBRA DE RAÚL GÓMEZ JATTIN}

Parto de una aclaración pertinente al título y me refiero a la idea del Caribe. Definir el Caribe resulta complejo y amplio en demasía. Para ello se requiere una delimitación histórica, geográfica y cultural. En lo histórico recordemos que su descubrimiento o encuentro, en el siglo XVI, fue una equivocación. Colón buscó las Indias Orientales y encontró las Indias Occidentales. En este espacio geográfico encontró unos hombres de un corazón amplio y dadivoso, quienes además de ofrecer sus cuerpos desnudos también ofrendan sus pertenencias, pues era y es su idiosincrasia: la generosidad y amplitud del corazón abierto como el mar, pero, a su vez, fueron y son temerarios y tenaces defensores de su cultura ante la presencia de quien quiera usurparla u ofenderla.

A partir del siglo XVI desfilan esos hombres llegados de España con la avidez del oro y la ansiedad de mujeres sensuales, de esas mujeres teñidas por el sol y de cuerpos esbeltos, que hicieron enloquecer a los españoles. Las tierras del Caribe son el escenario de esa lucha tenaz entre el hombre blanco usurpador y el nativo defensor de sus mujeres y de sus haberes. La respuesta del ser caribeño ante el atropello del conquistador es el ejercicio de la violencia sin reparos. De ahí que lexicalmente, la definición injusta de Caribe esté asociada con caníbal o un ser violento. De acuerdo con el Diccionario de Uso del Español de María Moliner (2007), Caribe se asocia con la idea y definición de salvaje u hombre bruto. A partir de tales nociones se justifican la esclavitud y todas las violencias que entraña esta forma de sometimiento, en tanto es el medio con el cual el blanco hace pleno el dominio de su presencia en esta región. Bajo el pretendidamente inocente propósito de educar a ese inculto e indómito hombre caribeño e inculcarle nuevas formas de vida y de pensamiento, se hace indispensable la institucionalización del castigo. Lo anterior dio pie para concebir que la buena educación se hacía con castigos, de ahí la triste frase que luego trazó un largo periplo por la pedagogía: "La letra con sangre entra". 
El hombre europeo, en este caso el español, creyó firmemente que la expoliación, la explotación y la exterminación de estos "salvajes" era un mandato divino, pues, según el blanco invasor, los hombres de estas tierras carecían de alma y, por lo tanto, se postulaban figuras del demonio. De igual modo, desde la perspectiva del catolicismo, los nativos americanos fueron considerados seres profanos por sus adoraciones a los ríos, las montañas, los árboles, el sol, la luna y las estrellas.

Al respecto de lo antes planteado, conviene señala lo siguiente:

Por una parte, entonces, Colón quiere que los indios sean como él, y como los españoles. Es asimilacionista en forma inconsciente e ingenua; su simpatía por los indios se traduce "naturalmente" en el deseo de verlos adoptar las costumbres del europeo. Decide llevarse algunos indios a España "porque volviendo sean lenguas de los cristianos y tomen nuestras costumbres y las cosas de la fe" (Todorov, 1997, pp. 50-51).

Esa visión de Colón contrasta con el pensamiento de los hombres de la Iglesia Católica, quienes impusieron violenta y sistemáticamente la religión. En este proceso de aculturación aparecen nuevas formas de expresión ideológica como la aparición de vírgenes y santos a lo largo y ancho del sur del continente. Lo anterior implicó que el listado de nombres del santoral se diera en correspondencia con los santos patrones de un pueblo, un país o una ciudad. Fue así como tuvieron lugar nombres como: Caridad, en Cuba; Guadalupe, en México; Marco, Juan, Tadeo, Jesús, José, Carmen y Fátima, entre otros, en "honor a algún santo católico".

En este sentido, recordemos La tempestad de William Shakespeare. En esta obra, Ariel, el salvaje noble, —quien vive en estado de libertad en un nuevo mundo; el cual imagina Montaigne- debe tributo a Próspero, quien se configura como su guía existencial, cultural y espiritual. En virtud de estos favores, a Ariel se le exige la obediencia y la sumisión.

Ariel.

iSalve, gran dueño! iMi respetable señor, salve!

Vengo a servir a tu mejor deseo,

sea el que vuele, nade, me sumerja

en el fuego o vaya cabalgando

sobre las rizadas nubes, por duro que sea

lo que ordenes,

Ariel y sus poderes se doblegan.

Próspero.

¿Has ejecutado, espíritu, puntualmente

la tempestad que te ordené?

Ariel.

Al pie de la letra... (Shakespeare, 1996, p. 66). 
Ariel es el espíritu del salvaje que poco a poco asimila de su maestro Próspero las sabias enseñanzas que este le ofrece desde otra visión cultural. Esto hace que su concepción del mundo se transforme y se adapte a las condiciones de un nuevo orden social y cultural. Es la confrontación del bárbaro y con el civilizado, de la cual, muchos años después, se nutren los escritores latinoamericanos para la generación de las novelas del Ilamado "Ciclo telúrico" del cual tenemos a: La Vorágine (1924), Doña Bárbara (1929) y Don Segundo Sombra (1926); obras que señalan el enfrentamiento entre el hombre y la naturaleza. En este encuentro está la presencia del personaje que llega de la ciudad, el personaje ilustrado que impone nuevas formas de pensamiento y combate la rudeza del nativo. Doña Bárbara, por ejemplo, en este sentido, ya no es ese personaje indócil y cerrero cuando cae en el embeleso de la palabra y en el porte ciudadano de Santos Luzardo. Arturo Cova seduce con la delicadeza de su lenguaje y enamora con la poesía. Hasta aquí se tienen frente a frente dos concepciones culturales, lamentablemente señaladas como la barbarie y la civilización. Ese hombre bárbaro deja profundas enseñanzas que aún son percibidas o perduran en el quehacer artístico como es la exaltación de la tierra y todas sus manifestaciones sobrenaturales, tal como es la comunicación con las plantas o con las aves, tal como lo vive Juan Primito en Doña Bárbara, tal como lo recrea el poeta Gómez Jattin: "Allí tuve una casa de techumbre pajiza/con agujeros en lo más alto/por donde el viento se colaba trayéndome/noticias del universo" (2004, p. 45). Quizás sin proponerse nos hace un guiño poético para poner en escena esa imagen del viento desde lo sobrenatural que tiene para el hombre del Caribe.

Desde otra dimensión del Caribe está la parte geográfica, esta región comprende no sólo la parte insular sino también la parte continental bañada por el mar Caribe y se extiende desde el sur de los Estados Unidos; la parte correspondiente a Miami, New Orleans hasta el nordeste del Brasil, tal como es Salvador y Río de Janeiro. Esta complejidad geográfica deviene en una variedad cultural, lingüística, social y política. En el ámbito cultural es clara la visión triétnica; determinante en la expresividad de la música, la idiosincrasia y el lenguaje, este último como generador de diferentes expresiones dialectales que hacen del Caribe una rica región lingüística y, que, posiblemente, redunda e influye en la poesía y en las composiciones musicales. De lo anterior se puede decir que Gómez Jattin se nutre para darle a su poesía esas imágenes alborozadas de luz y de color, como en estos versos: "porque sé cultivar naranjos y vegetales aún en la canícula" (2004, p. 3). Aquí aparece el campo en el esplendor del color amarillo y además con sutileza señala la tenacidad del hombre del campo.

En cuanto al sincretismo, producto de las tres culturas, está la música como una característica de la diversidad de actitudes del hombre frente a su historia y a su espacio, pues en la música el hombre del Caribe cuenta cómo llegó el negro a estas tierras, cómo fue el tráfico negrero y cómo lo pusieron a trabajar largas y extenuantes jornadas en los ingenios azucareros. Aparentemente, el 
Caribe musical es una ruta donde el disfrute y el goce del espíritu del ser caribeño hacen parte de su espíritu festivo, pero hay algo más profundo en los mensajes de las canciones y es esa historia cargada de nostalgia y de dolor. Tal como se siente al escuchar el jazz, en New Orleans; la bomba y la plena, en Puerto Rico; el merengue, en República Dominicana; la méringue, en Haití; el biguine, en Martinica; el Calipso, en Trinidad; el reggae y el movimiento rastafari, este último surgido a partir de la protesta del negro contra el blanco, la cual sucedió en 1930, en Jamaica; la gaita zuliana, en Venezuela; la cumbia, el porro y el vallenato en nuestro Caribe colombiano; el tamborito, en Panamá; el palo de mayo, en Nicaragua; la conga, el Son, la guaracha y la rumba, en Cuba; el danzón, en Veracruz, México; y, por último, la bossa nova, en Brasil. Son notas musicales que dan cuenta del oprobio y explotación al negro como también la nostalgia y la evocación de la tierra que aprendieron a amar. De ahí que el mar, las palmeras y la playa aparezcan reiteradamente en la música y poesía del Caribe y de ello hay versos en la poesía de Gómez Jattin que reafirman lo antes planteado.
Allí soñé escribir y cantar. Soñé llevarme a Cereté
A otros lugares. Deletreando en un papel blanco
A que gentes de otros ámbitos conocieran sus noches
Estrelladas
De espermas y fandangos cuando la Candelaria
Y esa alma gentil y bondadosa de ustedes mis amigos (2004, p. 45).

Es el encuentro entre la poesía y la música en la reafirmación de identidad cultural. Estos versos de la ensoñación telúrica de ese pueblo testigo de las andanzas del poeta como es Cereté y en él las fiestas a la Virgen de la Candelaria y el esplendor del fandango con las parejas que deleitan la vista al son de los tambores y las gaitas y el baile testigo mudo de amores y de seducciones.

Este recorrido musical reafirma una vez más el sentido cultural del Caribe en su unidad y diversidad; unidad en términos de visión del mundo, unidad en la cosmovisión del espacio y, más específicamente, en el sentido de asociación que hay entre el mar y la música. Esta hermandad se palpa en las voces de los boleristas y de las canciones de la música afro antillana, llámese son guaracha, chachachá, mambo, merengue etc. Al respecto, señalo un ejemplo: Vereda Tropical, del compositor Gonzalo Curiel:

Voy.../por la vereda tropical/la noche plena de quietud/con su perfume de humedad/ Y en.../la brisa que viene del mar/se oye el rumor de una canción/canción de amor y de piedad. / Con ella fui/noche tras noche/hasta el mar/para besar/su boca fresca de amor... (Leal, 1992, p. 63). 
Esto es la música, el mar y el amar, trío que invita al éxtasis de la contemplación de la amada, de la llanura marina, de la noche y de la pasión. Estos son los componentes implícitos o sagazmente escondidos en la poesía de Gómez Jattin, los cuales se abren o se descubren cuando leemos del poema Ombligo de luna los siguientes versos: "Es tarde amor. El mar trae tormenta/Hay una luna pálida que recuerda tu ombligo/Y unas nubes livianas y pesadas como tus manos/beben sedientas Así cuando yo sobre tu boca muero" (2006, p. 107). En la canción de Curiel está el encuentro amoroso bajo la complicidad de la noche y el rumor del mar, mientras en la poesía de Gómez Jattin hay abandono y recuerdos.

También está la canción Isla del encanto del compositor E Hernández y la interpretación de la Orquesta Broadway. Aquí se nos ambienta el paisaje del mar en una noche de amor. "Cuando la luna cae sobre tus palmeras/y en tus playas el mar agita sus olas,/el firmamento brilla su mejor estrella/para darle luz a su preciosa nena". Si bien es la exaltación a Puerto Rico o la "Isla del Encanto", como también se conoce, de igual forma, permite la relación entre espacio idílico y mujer, pues la canción nos remite a una nena como es la isla. Gómez Jattin nos presenta ese mismo sentimiento cuando dice: "Aquel amor de fiebre y de tormento/aquel estar pendiente de la luna entre los cocoteros/por si ella me traía presagios de tu cuerpo. Pero en vano/Pero estaba demasiado enfermo para soportar/la intimidad de las caricias. No hubieras conocido/ en mí sino el temblor de un poeta y de su

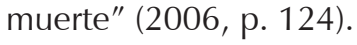

En este punto, se hace necesario tener en cuenta que "La relación de los hombres insulares con el mar es una de las principales fuentes de referencia contextual, que determina de manera inmediata su concepción del mundo" (Giménez, 1990, p. 162). El poeta y el músico le cantan al mar, lo sienten como parte de su esencia espiritual, como el espacio para la intimidad. "Ante el mar encendí mis primeros poemas/ defendiendo mi causa de sus asolaciones..." (Gómez Jattin, 2006, p. 53). El mar es determinante en la visión cultural en el pensamiento del ser caribeño. En lo que corresponde a Colombia, esta denominación se hace extensiva al hombre costeño o de la Costa Atlántica o del Caribe que comprende o abarca los departamentos de Sucre, Córdoba, Magdalena, Bolívar, Cesar, Atlántico, La Guajira y Las islas de San Andrés y Providencia.

En la línea de estas apreciaciones está el poema De mi valle, aquí Gómez Jattin nos exalta la presencia de ese pueblo del departamento del Caribe colombiano en resuello de los instrumentos que pelean con el viento y convierten a ese pueblo en una isla de recuerdos y de músicas. Dicen los versos: "Existe San Pelayo/un recodo milagroso del tiempo/una isla de música en el letargo del valle/glorioso San Pelayo/de trompetas y tambores" (2004, p. 61). Poesía y música unen los sentimientos de ese espíritu y nada más evocador de su tierra en el espíritu del caribeño que los compases de un acordeón cuando escucha canciones como El cantor de Fonseca, del compositor Carlos Huertas, cuando dice: "Alguien me dijo 
de dónde es usted/que canta tan bonito esa parranda, /óigame compa usted no es del Valle/del Magdalena, ni de Bolívar,/ pues se me antoja que sus cantares/ son de una tierra desconocida. /y yo le dije si a usted le inspira/saber la tierra de donde soy/con mucho gusto y mucho honor/yo soy del centro de La Guajira/Nací en Dibuya, frente al mar Caribe,(...)"

La poesía de Gómez Jattin contagia de alegría, de música y de sabor. Responde, en suma, a ese sentimiento que expresa la cosmovisión y la cultura de esa región del país. De tal modo que "A Gómez Jattin le importa, de modo casi literal internarse en sus textos, adoptar la identidad que estos le conceden" (Monsiváis, 2004, p. XIX). Por eso cuando se habla del costeño se dice de él que es una persona amplia, descomplicada, amigable, sincera y alegre. De ahí que los poemas de Gómez Jattin sean una constante imagen de ese calor humano inherente a la condición del ser caribeño, bien sean las metáforas de la ensoñación o de la contemplación con que se disfruta la llanura marina o bien sean las formas de convivencia con el medio desde lo hostil hasta la complacencia estoica de la adversidad.

Percy Bysshe Shelley dice que la poesía siempre va acompañada de placer y esto se cumple en la poesía de Gómez Jattin como si su espíritu se abriera para recibir la alegría que brinda el mar en su infinidad, la naturaleza en su prodigalidad y la sabiduría de la vida que va entrelazada con el deleite de la misma. En "Serenata", Gómez Jattin tiende una invitación al placer, al disfrute de la vida, pues en él la vida adquiere sentido cuando se escucha la música y se ama. "Asómate amor mío/que el cielo ha encendido un fandango/en su comba lejana y no hace frío/el viento musica entre árboles un gemido/que parece tú sintiéndome el placer" (2006, p. 109). Cabe resaltar que del sustantivo música nace un verbo y de allí la validez del verso: "el viento musica entre árboles un gemido". Así, también, en estos versos hay una abierta manifestación de amar bajo la compañía de la noche y del viento que canta o musita el encuentro de los amantes. En esta unión el cielo está complacido y el fandango sirve de complemento a la contemplación del amor.

Gómez Jattin logró, en la poesía colombiana de hoy, tocar el sol. Era una panteísta exuberante, vital y dionisiaco, que cantó y bailó, en las riberas del río Sinú, en Cereté, en Cartagena, en la costa Atlántica, al transformar a todos los seres, del hombre a la gallina, en dioses.

Logró darle tal calor y tal vitalidad a nuestra esmirriada poesía, que leerlo era palmotear de júbilo, reír y solazarnos en el calor dichoso de su música, surcada toda ella con los rasgos de su cultura y el folclor del Caribe (Cobo, 2003, p. 491). 
En este aspecto es necesaria la presencia ineludible de la música y su cómplice el mar, pues componen una pareja indisoluble en la visión del poeta caribeño. La poesía de Gómez Jattin no es la excepción, pues hace de la poesía un culto al ritmo, una adoración a la palabra en su esencia sonora y una expresión del ser caribeño en lo más alto de su espíritu festivo. Su poesía es un ritual que desborda las leyes de lo prohibido ya que en ella hay una invitación al goce, al desenfreno, tal como fue su vida y su obra. Roberto Burgos Cantor recuerda que:

Entonces Raúl compuso una canción que a mí me pareció muy triste.

Yo vengo de San Pelayo

A contarles mis historias.

En menos que canto un gallo

Cuento olvidos y memorias.

El hijo que tú esperabas,

Pobrecito, nació muerto.

Y seguía, esto es lo que yo recuerdo. Era impresionante, porque uno se dice, bueno, ¿Qué tiene qué ver eso con la obra de Kafka? (2004, pp. 225226).

Por ejemplo, del poeta Rómulo Bustos, nacido en la población de Santa Catalina de Alejandría en el departamento de Bolívar, tomo los siguientes versos: “El rostro de la luna El gozoso/plumaje de los árboles/la suave lluvia. El mar oleando sus fogajes/ ¿Mas qué son todas las galas/ante el rostro jubiloso de un arcángel/ suspendido su respiro en la empinada ebriedad del vértigo?" (2004, p. 93). En estos versos la presencia de lo erótico es más sutil, pues se desvía la atención desde el componente religioso que también tiene un ingrediente erótico para hablarnos de la ebriedad del vértigo que es la metáfora del Eros.

Ahora bien, la apreciación global del Caribe me lleva a la reflexión de lo que es el Caribe colombiano como expresión de sentimiento que permite la diferenciación con respecto a los otros. En el Caribe están presentes las manifestaciones humorísticas, sexuales, telúricas, amistosas, de compadrazgo, musical y lingüística que los diferencian del otro. Raúl Gómez Jattin presenta los rasgos de una visión caribeña en la dimensión sui generis, muy propia de su poesía, que lo hace diferente, a veces inexplicable, o malinterpretado o mal entendido en el medio poético.

De ahí que veamos paso a paso cómo se manifiesta la poesía de Gómez Jattin en el marco de una visión poética del Caribe. Al respecto tomo el caso del humor en su poesía o como se conoce en el Caribe con la palabra mamagallismo. Por el momento vayamos a iqué es el humor? Es una cualidad del ser que consistente en mostrar lo que hay de cómico o burlesco en el otro o en las cosas. El humor se asocia más con lo serio, para que haya humor se necesita la reflexión y eso lo que lo diferencia del chiste. Este suceso degrada; el humor redime, consagra las cosas, los momentos y el ser en la trascendencia del pensamiento. Una cualidad del 
humor es la puesta en escena del yo, de su esencia tanto cultural como social en la relación con el otro, tal como lo dice Macedonio Fernández con respecto a la sutileza de la palabra: "En el humorismo conceptual, en cambio, funciona siempre el autor con dos elementos optimísticos, además de la temática: su exhibición de facultad de ingenio..." (1988, p. 122). Entendemos la poesía de Gómez Jattin en su contenido humorístico cuando penetramos en la profundidad de la palabra y lo poético que ella asume. Cuando abrimos un libro de él y nos encontramos con el poema que dice: "COMO YERBA FUI y no me fumaron" (2006, p. 9) los interrogantes o las inquietudes saltan a la vista. El humor o el mamagallismo en la poesía de Gómez Jattin soporta una dualidad en la intención interlocutora. El primer nivel funciona en la asociación yerba y fumar, entonces se asocia con el vicio de la marihuana. Se habla de la yerba que, como es apenas obvio, tiene diversas acepciones, de acuerdo con el medio y la época. Papel de bambú, en Puerto Rico, manta de bandera en los viejos de Barranquilla, la maracachafa en Cali de los años setenta, el cachimbo que en Venezuela es pipa y deviene en el cigarro de marihuana, la mota en México, la chicharra, el porro, el embale o el bareto. Se ve claramente, entonces, que la primera impresión de este poema es la alusión al vicio.

El segundo nivel interpretativo de este poema tiene que ver con la referencia a la obra poética de Fernando Pessoa. Hay una modificación burlesca o mamagallista en el mejor sentido caribeño. El poema de Gómez Jattin asume el pastiche o la imitación burlesca de la obra de Pessoa y en esa imitación funciona la reflexión como esencia de lo humorístico. "Como yerba fui y no me fumaron" se deja leer en la profunda esencia poética del texto pessoano. Una relación detallada de los dos poemas deja al trasluz el sentido de la desesperanza y de la muerte y en el caso de Gómez Jattin trasluce ese dejo mamagallista a la muerte y a la desesperanza.

El poema de Pessoa "Escrito en un libro abandonado en un viaje" asume la dimensión de lo efímero de la vida y la trascendencia del tiempo en esa sinrazón de la existencia.

Vengo de tierras de Beja

voy al centro de Lisboa.

No traigo nada y no encontraré nada.

Tengo el cansancio anticipado de lo que no encontraré, y la saudade que siento no está en el pasado ni en el

Futuro.

Dejo escrita en este libro la imagen de mi designio muerto:

Fui como hierbas y no me arrancaron (1987, p. 111). 
Si nos detenemos más en la intención del pastiche encontramos que las afinidades entre los dos poemas traslucen aspectos del pesimismo en la dimensión tanto desesperanzada como humorística.

Tabla No. 1.

\begin{tabular}{ll}
\hline Fernando Pessoa & Raúl Gómez Jattin \\
\hline Vengo de tierras de Beja & $\begin{array}{l}\text { YO TENGO PARA TI mi buen amigo } \\
\text { Un corazón de mango del Sine. }\end{array}$ \\
\hline No tengo nada y no encontraré nada & Yo no tengo presente/sólo pasado y futuro. \\
\hline $\begin{array}{l}\text { Tengo el cansancio anticipado de lo que } \\
\text { no encontraré }\end{array}$ & $\begin{array}{l}\text { El cuerpo de esa tarde/ es el fluido tenso } \\
\text { entre el pasado y el futuro. }\end{array}$ \\
\hline $\begin{array}{l}\text { Y la saudade que siento no está en el } \\
\text { pasado ni en el futuro }\end{array}$ & \\
\hline $\begin{array}{l}\text { Dejo escrita en este libro la imagen de } \\
\text { mi designio muerto }\end{array}$ & $\begin{array}{l}\text { Siento escalofríos de ti } \\
\text { hermana muerte. }\end{array}$ \\
\hline
\end{tabular}

Fuente: Elaboración propia.

En el cotejo de la poesía de Pessoa y Gómez Jattin se entretejen imágenes de la desesperanza, de la muerte, de la angustia; imágenes en el soporte del existencialismo de la poesía de Pessoa como en el humorismo de Gómez Jattin. Esa visión poética del Caribe a partir del humor destaca el pensamiento, juega con los atributos del otro, recrea un ámbito, paladea la muerte, coquetea con el tiempo y establece la siguiente síntesis: el humor en la visión poética del Caribe es el soporte de cómo lo trascendente se degrada, no se le rinde culto sino a través de la risa y de lo burlesco. Según lo consignado, el mamagallismo constituye en el Caribe una expresión social y cultural.

En una relación más amplia del sentido del humor como visión poética del Caribe apelo a otros poetas del mismo ámbito. Me refiero a Nicolás Guillén, Palés Matos y Luís Carlos López, respectivamente de Cuba, Puerto Rico y Colombia.

Mulata.

Ya yo me enteré, mulata,

mulata, ya sé que dise

que yo tengo la narise

como nudo de cobbata (Guillén, 1980, p. 10).

La pareja hace pública la cotidianidad a partir de la comparación burlesca de la nariz con el nudo de corbata, pero la similitud va más allá de la simple relación, pues ella implícitamente hace alarde del rumor —expresión muy propia del Caribe - para la divulgación del apodo. 
Preludio en boricua.

Con cacareo de maraca

y sordo gruñido de gongo,

el telón isleño destaca

Una aristocracia macaca

a base de funche y mondongo (Palés,1988, p. 146).

Versos en donde el humor juega un rol importante en la desacralización de la jerarquía aristocrática. La palabra "macaca" soporta el peso de la burla, pues admite la significación de simio y a la vez de deforme, atrasada e hipócrita. La desacralización radica en el espíritu festivo con que se celebra la presentación de la aristocracia.

Postura difícil

Siento el paisaje, pero la vecina, noble señora muy devota, muy de mi pueblo, me ofrece su anodina

conversación de ama de llaves (López, 1979, p. 120).

Desde el mismo título, Luís Carlos López nos presenta la idea de la burla; es una dama mediocre y esto obedece a la beatería y a los rezos, pues sólo tiene conversación para la crítica acerba o mal intencionada. Los versos ofrecen ese ambiente mediocre, cotidiano y anodino de las gentes. Pues bien, este conjunto de versos se relacionan con el humor trasgresor que hay en la poesía de Gómez Jattin.

El otro aspecto trascendente en la visión poética del Caribe es el sexo y Raúl Gómez Jattin hace de él motivo de burla, de sonrojo, de escarnio y de juego. Pero en todos estos aspectos destacan la ironía y el sarcasmo. De burla en tanto desacraliza la intimidad de los amantes o de la pareja; de juego en la medida que entra en el pensamiento del otro y lo reta a que asuma una posición o defina la moralidad en el tema de la zoofilia; de escarnio, en cuanto la mujer de cuerpo grotesco o el hombre que mantiene su homosexualidad oculta son tratados con la crudeza del lenguaje, no hay en aquí la mediación de las imágenes o de la metáfora que atenúe la palabra soez o la desfachatez con que se trata el acto sexual. Estas situaciones que se presentan en la poesía de Gómez Jattin se comprenden y se interpretan desde lo que plantea Rómulo Bustos Aguirre en "El resplandor ético de la palabra obscena" cuando Bustos, a propósito del siguiente poema precisa que: "la buena conciencia del lector es asaltada por el ingreso de la práctica del bestialismo en las praderas sublimes de la poesía. El lugar semántico de este elemento ocurre, precisamente en esa tensión entre Memoria Vigilante y Desmemoria Excluyente" (1998, p.12). 


\begin{abstract}
TE QUIERO BURRITA/Porque no hablas/Ni te quejas/Ni pides plata/Ni lloras/ $\mathrm{Ni}$ me quitas un lugar en la hamaca/Ni te enterneces/Ni suspiras cuando me vengo/Ni te frunces/Ni me agarras/Te quiero a ti sola/Como yo/Sin pretender estar contigo/Compartiendo tu crica/Con mis amigos/Sin hacerme quedar mal con ellos/Y sin pedirme un beso (2006, p. 19).
\end{abstract}

No es la animalidad en sí o per se, no es la zoofilia en la más simple exposición de una cultura Caribe, sino es la actualización o puesta en escena de unas prácticas sexuales legendarias y anejas al tiempo y a la cultura. Veamos que desde los tiempos remotos ya existía esta práctica en las comunidades primitivas. Al respecto leamos lo que La Biblia prohíbe en el Levítico; capítulo 18, versículos 23 y 24: "Con ningún animal tendrás ayuntamiento, haciéndote impuro con él, ni mujer alguna se pondrá delante de animal para ayuntarse con él, es perversión. En ninguna de estas cosas os haréis impuros, pues en todas estas cosas se han corrompido las naciones que yo expulso de delante de vosotros y también la tierra fue contaminada" (1995, p. 167). Con lo anterior queda descartada la lectura coercitiva de este poema, pues estos versículos exorcizan al poeta y le quitan ese remoquete de perverso o maldito.

Una lectura atenta del poema nos ofrece la humanización del animal, pues la burrita conlleva el peso de la comprensión, del amor y de la ternura a partir de las contradicciones que las palabras agencian en el poema. La burrita no habla, no Ilora, no se enternece, pero le es fiel, respetuosa y reservada, tal como se presenta en la idiosincrasia de la cultura del Caribe.

Ahora veamos que en cada de una de estas expresiones se oculta una manifestación o una condición del ser en sus momentos más trascendentales. Precisamente, Orlando Fals Borda, a propósito del sexo dice que:

Una fuente de esta dinámica cultura costeña ha sido nuestra actitud ante la sexualidad. Viéndolo bien, el sexo no era ni es un problema entre nosotros los costeños, ni siquiera en relación con conocidas costumbres de grupos de juegos juveniles. Marica, sabemos que el burrear ayuda a desarrollarse al hombre. iSe apendeja el maricón que no lo hace! Todos los estamentos de nuestra sociedad toleran la funcionalidad madurante del burreo, con la diferencia de que aquí somos lo suficientemente francos en admitirlo, mientras que en otras partes los hipócritas disimilan su propia bestialidad con otros animales. Y también toleramos o comprendemos con humanidadaunque con alguna sonrisa pícara- las situaciones incómodas de las "queridas", de los amantes reservados de viudas y jóvenes urgidas. Eso de levantar mujer u hombre, marica, es cosa diaria que a nadie preocupa (1979, p. 151b-152b). 
Gómez Jattin, desde esta visión, plantea una imagen del mundo caribeño, especialmente en cuanto al hombre de nuestra Costa Atlántica. El desenfado, la sencillez y espontaneidad abren las puertas de su mundo para la comprensión del otro, para la interpretación de su cultura. Su poesía es un acto dialógico, un acto de acercar los mundos culturales; el mío y el ajeno, de entender la intención del otro a partir del acto poético. Y tal como lo señala Fals Borda, el hombre de la costa no tiene aprensión para el trato con el sexo, pues éste es parte de su vida cotidiana.

En América Latina, ya algunos escritores lo habían intentado. Así pues, Vargas Llosa en La ciudad y los perros (1963) menciona las relaciones sexuales de los alumnos internos del Leoncio Prado con la malpapeada y con las llamas. También está la referencia a la cultura brasilera como en el caso de la novela Estancia modelo (1975), de Chico Buarque. Remito el lector al texto de la novela de Buarque para mayor ilustración del caso pertinente. Aunque es una novela que apela a lo grotesco, a su vez se constituye en una alegoría para darnos una idea sobre la profundidad de la situación del pueblo brasilero, sometido a una dictadura, pero presentado de una manera irritante y divertida. La novela se constituye en una parodia de las obras de Swift y de Orwell y de esta manera no cae en el panfleto.

Fue confinada en el establo con sus compañeras de pura sangre. No tenía sentido abandonar a las hembras finas a la buena del campo pescándole garrapatas y gonorrea. Y Juvenal comprobó que es más dispendioso transportar alimentos para los animales en el campo que abrigarlos y engordarlos en recintos cerrados. Ellas, las vacas, no llegaron a manifestar sus aflicciones y anhelos. Antes de sondear sus opiniones, dudas y palpitaciones, Juvenal les impuso la sublime misión de los hijos (Buarque, 1975, p. 43).

Culturas que se tocan en el profundo sentido de la existencia, acercamientos en las conductas de los seres humanos que en un tácito diálogo viven la vida en la transparencia de la cultura. Quizá desde afuera se censure desde la óptica de la moral social y cultural, pero es precisamente desde la perspectiva de la cultura Caribe que podemos realizar una comprensión de este comportamiento de sus gentes, sin que ello produzca una trasgresión en el pensamiento. El poema de "Te quiero burrita" se aprecia desde la frontera cultural de la palabra muy propia del Caribe con respecto al sexo con los animales. Cuando tal situación ocurre hay un desprendimiento del prurito moral o religioso y se adentra en los ámbitos de la cultura costeña o Caribe y en ella se disfruta la fiesta con la palabra, bien sea en el humor o en efecto de las imágenes. El deleite del humor con esa expresión de "te quiero burrita porque no hablas" o en el placer de las imágenes como en los versos de "te quiero a ti sola/como yo/sin pretender estar conmigo" en ese erotismo que desdobla la conciencia y se cae en un inocente juego entre lo sentimental y el ritual liberador del sexo. Es el verso retador que pone al descubierto la intimidad de la cultura Caribe desde lo expresivo del sexo y la mirada del otro desde la 
censura. "Te quiero burrita" mueve a la risa abierta o al paso trasgresor de la lectura para el conocimiento de la esencia popular del sexo con animales.

En síntesis, se infiere que la poesía de Gómez Jattin es un canto de alabanza a las expresiones culturales de su tierra a partir de imágenes que recrean la memoria y en ella los recuerdos de su infancia en los patios, los juegos con sus amigos y las parrandas interminables y pantagruélicas animadas por el vallenato. De este modo, el lector entiende que nos encontramos ante un poeta trasgresor de un orden social y en ese acto liberador con la palabra nos invita al disfrute de la cultura caribeña en los círculos turbulentos del lenguaje poético a partir de las trampas que nos tiende la aparente pasión mundana, pues la cultura descansa en la coerción de los instintos $\Phi$

\section{REFERENCIAS}

Buarque, Ch. (1975). Estancia Modelo, Buenos Aires: Ediciones La Flor.

Burgos, R. (2004). en José Antonio de Ory Ángeles clandestinos. Una memoria oral de Raúl Gómez Jattin, Bogotá: Editorial Norma.

Bustos, R. (1998). "El resplandor ético de la palabra obscena". El Magazín Dominical. El espectador. pp. 11-13.

Cobo, J. (2003). Historia de la poesía colombiana, Siglo XX. De José Asunción Silva a Raúl Gómez Jattin. Bogotá: Villegas editores.

Fals, O. (1979). Historia doble de la Costa. Tomo 1. Bogotá: Carlos Valencia, editores.

Fernández, M. (1988). "Una teoría de la humorística". En M. E. Mudrovic (Comp.). Espejo en el camino. México: Universidad Nacional Autónoma de México.

Giménez, L. (1990). Caribe y América Latina. Caracas: Monte Ávila Editores.

Gómez, R. (2004). Amanecer en el Valle del Sinú. México: Fondo de Cultura Económica.

Gómez, R. (2006). Poesía Completa. Cartagena: La Casa de Asterión.

Guillén, N. (1980). Sóngoro Cosongo y otros poemas. Madrid: Alianza editorial.

La Biblia (1995). Bogotá: Sociedad Bíblica Colombiana. 
Leal, N. (1992). Boleros. La canción romántica del Caribe, (1930-1960). Caracas: Editorial Grijalbo.

López, L. (1979). Obra poética. Bogotá: Carlos Valencia editores.

Monsiváis, C. (2004). "La vida: valorar al loco". Amanecer en el Valle del Sinú. Antología poética. Bogotá: Fondo de Cultura Económica.

Palés, L. (1988). Poesía completa y prosa selecta. Caracas: Editorial Ayacucho.

Pessoa, F. (1987). Antología de Álvaro de Campos. Madrid: Alianza Editorial.

Shakespeare, W. (1996). La tempestad. México: Universidad Nacional Autónoma de México.

Todorov, Z. (1997). La conquista de América. El problema del otro. México: Siglo XXI editores. 